CONDOM USE

\title{
Lack of recent condom use among detained adolescent males: a multilevel investigation
}

\author{
R Crosby, L F Salazar, R J DiClemente
}

See end of article for authors' affiliations

.....................

Correspondence to: Richard Crosby, PhD College of Public Health, University of Kentucky, 121 Washington, Avenue, Room $111 \mathrm{C}$, Lexington, $\mathrm{KY}$ 40506-0003, USA crosby@uky.edu

Accepted for publication 8 April 2004
Sex Transm Infect 2004;80:425-429. doi: 10.1136/sti.2004.009639

Objective: To investigate multiple levels of influence with respect to the lack of recent condom use among a high risk sample of adolescent males recruited from short term detention facilities.

Methods: A cross sectional survey of 231 adolescent males serving, predominantly, short term detention sentences. Assessments were conducted using audiocomputer assisted self interviewing. Condom use during the most recent sexual event was assessed as well as 20 potential correlates of not using condoms. Correlates were assessed within five levels of causation: personal, relational, peer affiliation, family, and societal.

Results: Nine correlates achieved bivariate significance $(p<0.05)$. Of these, the personal level correlates were particularly important in a multivariate model. The motivation subscale from the Condom Barriers Scale was the strongest multivariate correlate of recent condom use. Adolescents scoring below the median were about 3.4 times more likely to report lack of recent condom use $(p=0.0006)$. Adolescents indicating they had ever caused a pregnancy were about 2.5 times more likely to report lack of condom use $(p=0.02)$. Finally, those reporting their peers did not use condoms were about twice as likely to report lack of use $(p=0.048)$.

Conclusion: Upon investigating multiple levels of potential influence on condom use, the multivariate findings suggest that personal level factors may be the most important determinant of non-use among adolescent males in short term detention facilities. Although structural changes may be needed to influence some forms of safer sex behaviour, direct intervention with adolescent males may be justified to favourably alter determinants of condom use.
1 $\mathrm{n}$ the United States, adolescents disproportionately acquire sexually transmitted infections (STIs) ${ }^{1-3}$ Among adolescent males, those detained for legal offences represent a highly vulnerable population for the acquisition and transmission of STIs. ${ }^{14-7}$ Unfortunately, few recent observational studies investigating STI associated risk behaviours of adolescent male detainees have been published. ${ }^{78}$ Thus, research informing the design of programmes for this vulnerable population is needed.

Behavioural investigations can be targeted towards multiple levels, including the personal level, relational level, social normative influences (especially peers), familial influences, and societal structures. ${ }^{9}$ The identification of personal level factors may be particularly important because these may be highly amenable to change. However, targeting personal level factors in isolation may be problematic if other levels are also primary determinates of adolescents' sexual risk behaviour. Given the potential value of condom use for the prevention of STIs, $^{10}$ this study investigated multiple levels of influence with respect to the lack of recent condom use among a high risk sample of adolescent males recruited from short term detention facilities.

\section{METHODS}

Study sample

Eight detention facilities located in the state of Georgia cooperated in the administration of a cross sectional survey. Between October 2001 and July 2003 research assistants screened detained adolescents for eligibility. Adolescents were eligible if they were 14-18 years old, provided assent, and if their parents provided consent. Of 682 deemed eligible, 554 volunteered $(82 \%)$. For this study only data from 231 males, responding to a question about recent condom use, were analysed. The institutional review board at Emory University approved all procedures.

\section{Data collection}

Based on evidence suggesting decreased reporting bias, ${ }^{11-13}$ assessments were conducted using audio computer assisted self interviewing (A-CASI). By providing a voice track that delivered each question to adolescents through headphones, A-CASI technology may have reduced problems that otherwise would have been posed by illiteracy.

\section{Measures}

The outcome measure was assessed by asking adolescents if they used a male condom, "the very last time you had sex." The use of the most recent sexual event for a recall period may foster improved accuracy (and therefore validity) of the responses. In addition, 20 correlates were assessed.

Although a comprehensive, multilevel, assessment of potential correlates associated with lack of recent condom use would be a massive undertaking, an abridged assessment is clearly possible. To achieve this goal five levels were identified: (1) personal, (2) relational, (3) peer affiliations, (4) family, and (5) societal. Three or four variables were measured within each of these five levels. In addition, we assessed two critical demographic variables (age and race/ ethnicity) and two variables capturing previous risk behaviour (ever causing a pregnancy and ever having an STD).

Personal level

The Condom Barriers Scale (CBS $)^{14}{ }^{15}$ was used to assess three personal level variables. A recent study suggests that the CBS

Abbreviations: A-CASI, audio computer assisted self interviewing; CBS, Condom Barriers Scale; STI, sexually transmitted infections 
may have strong construct validity for adolescents ${ }^{15}$; however, construct validity among a detained adolescent males has not been established. Firstly, the CBS contained a four item scale $(\alpha=0.69)$ that measured motivation to use condoms. Questions included items such as "I don't want to put a condom on" comprised this subscale. Next, the CBS contained an eight item subscale $(\alpha=0.86)$ that measured pleasure barriers to condom use-for example, "Condoms don't feel good" and "I feel closer to my partner without a condom." Finally, a six item subscale $(\alpha=0.74)$ measured adolescents' perceptions regarding access associated barriers to condom use-for example, "I would be embarrassed to buy condoms or ask for them" and "Condoms cost too much." Response alternatives to all CBS measures were provided on a visual scale ranging from (1) "strongly disagree" to (4) "strongly agree." Further, based on evidence that impulsivity may be an important correlate of adolescents' lack of recent condom use, ${ }^{16}$ a three item scale $(\alpha=0.71)$ measured impulsivity-for example, "Life without danger is dull."

\section{Relational level}

A seven item subscale $(\alpha=0.88)$ of the CBS measured adolescents' perceptions regarding potential partner associated barriers to using condoms-for example, "If I used a condom, my partner would think I did not trust her." Further, a five item scale $(\alpha=0.91)$ measured the frequency of communication (past 2 months) between adolescents and their sex partners with respect to condom use, preventing STDs, AIDS, and pregnancy. This scale has been used in related investigations of condom use. ${ }^{17}$ In addition (based on evidence that contraceptive use and condom use are inversely associated $^{18}$ ), adolescents were asked whether their recent (past 2 months) sex partners were using the pill or an injectable contraceptive (Depo Provera).

\section{Peer affiliations}

Based on evidence suggesting that gang affiliation may be a risk factor for not using condoms, ${ }^{19}$ we asked adolescents if they had ever belonged to gang. Further, we asked adolescents to respond to two statements: "Most of the guys I know never use condoms when they have sex." and "Most of the guys I know will cause a pregnancy." Response alternatives were provided on a visual scale ranging from (1) "strongly agree" to (4) "strongly disagree."

\section{Family level}

Although several family level factors may be important, ${ }^{20}$ we selected three for the current study: residing with at least one parent, discussing safer sex with a parent, and perceived family support. A five item scale $(\alpha=0.84)$ measured how frequently adolescents discussed condom use and preventing STDs, AIDS, and pregnancy with parents. A four item scale $(\alpha=0.88)$ measured their perceptions of family support. ${ }^{21}$

\section{Societal level}

Based on the potential for increased availability, we asked adolescents if their school had a clinic that distributed condoms. Next, as a proxy measure of their family income, we asked adolescents if they qualified for a free or reduced price lunch at school. Finally, as a proxy measure of a risky social environment, we asked adolescents if they had witnessed extreme violence (for example, severe beatings, shootings) in the past year.

\section{Data analysis}

Owing to markedly skewed distributions, correlates assessed on a continuous scale were dichotomised by performing a median split. A median split divides a continuous distribution into two portions that come as close as possible to comparing $50 \%$ of the scores on one side of the distribution to $50 \%$ on the converse side (for example, high versus low; greater versus less). Bivariate associations between the 20 assessed correlates and lack of recent condom use were assessed by prevalence ratios, their $95 \%$ confidence intervals, and respective $\mathrm{p}$ values. Correlates achieving significance $(p<0.05)$ were entered into forward stepwise logistic regression model. Multivariate significance was defined by $95 \%$ confidence intervals and $\mathrm{p}$ values of less than 0.05 .

\section{RESULTS}

\section{Characteristics of the sample}

Average age was 15.5 years (SD 0.95 years). The median level of education was completion of the ninth grade. Forty per cent identified themselves as white and non-Hispanic, $41 \%$ as African-American and non-Hispanic, $4.4 \%$ as white and Hispanic, $8.0 \%$ as African-American and Hispanic, with the remainder identifying as members of other races. Adolescents had been serving their current detention sentence for a median of 13 days. Seventy per cent of the adolescents reported serving at least one detention sentence previously. Condom use during the most recent sexual encounter was reported by nearly two thirds $(62.8 \%)$, leaving $37.2 \%$ who had not used a condom.

\section{Bivariate associations}

Table l gives bivariate associations between the assessed correlates and recent condom use. Of the 20 measures, nine achieved significance. Table $\mathrm{l}$ also serves a descriptive purpose by showing the proportions of those with, and those without, the potential risk factor who had not used a condom during their last sexual encounter. Of note, nine of the 11 non-significant associations were based on remarkably similar proportions (that is, the difference between groups was extremely small).

One historical factor achieved significance; adolescents who had ever caused a pregnancy were more likely to report they had not used condoms. Three of the four personal level factors achieved significance (each was a subscale of the CBS). Low motivation, greater perceived pleasure barriers to condom use, and greater perceived access barriers to condom acquisition were each associated with not using condoms. The only relational level correlate achieving significance was also a subscale of the CBS. Adolescents perceiving greater partner barriers to condom use were more likely to report they had not used condoms. Condom use was less likely among those who reported affiliations with peers who do not use condoms. Also, condom use was less likely among those reporting their peers had caused a pregnancy. Not residing with at least one parent was the only significant family level correlate of not using condoms. Finally, the proxy measure of income (qualifying for a free or reduced price lunch at school) was associated with lack of condom use.

\section{Multivariate associations}

The multivariate model was significant $(\mathrm{p}<0.0001)$ and fitted the data exceedingly well (goodness of fit index $\chi^{2}=2.00$, $\mathrm{df}=5, \mathrm{p}=0.85$ ). However, only three of the nine variables entered retained significance. The motivation subscale from the CBS measure was the strongest multivariate correlate of recent condom use. Adolescents scoring below the median were about 3.4 times more likely to report lack of recent condom use (adjusted odds ratio $(\mathrm{AOR})=3.39 ; 95 \%$ $\mathrm{CI}=1.68$ to $6.84 ; \mathrm{p}=0.0006)$. Adolescents indicating they had ever caused a pregnancy were about 2.5 times more likely to report lack of condom use $(\mathrm{AOR}=2.47 ; 95 \% \mathrm{CI}=1.14$ to 5.36; $p=0.02$ ). Finally, those reporting that their peers did 
Table 1 Bivariate associations between assessed correlates and lack of recent condom use among detained adolescent males

\begin{tabular}{|c|c|c|c|c|}
\hline Correlate (n) & $\%$ not using condoms & $\mathbf{P R}^{*}$ & $95 \% \mathrm{Cl}$ & p Value \\
\hline \multicolumn{5}{|c|}{$\begin{array}{l}\text { Demographic and history factors } \\
16 \text { years of age or older }\end{array}$} \\
\hline Yes & 40.5 & & & \\
\hline No & 33.3 & 1.21 & 0.86 to 1.71 & 0.26 \\
\hline \multicolumn{5}{|c|}{ Racial or ethnic minority } \\
\hline Yes & 33.1 & & & \\
\hline No & 43.5 & 0.76 & 0.55 to 1.06 & 0.11 \\
\hline \multicolumn{5}{|c|}{ Ever caused a pregnancy } \\
\hline Yes & 55.2 & & & \\
\hline No & 30.8 & 1.79 & 1.30 to 2.47 & 0.001 \\
\hline \multicolumn{5}{|c|}{ Ever had an STD } \\
\hline Yes & 46.7 & & & \\
\hline No & 36.6 & 1.28 & 0.72 to 2.25 & 0.43 \\
\hline \multicolumn{5}{|c|}{ Personal level factors } \\
\hline \multicolumn{5}{|c|}{ Motivation to use condoms } \\
\hline High & 20.6 & & & \\
\hline Low & 51.7 & 2.51 & 1.67 to 3.79 & 0.0001 \\
\hline \multicolumn{5}{|c|}{ Pleasure barriers to condom use } \\
\hline More & 50.9 & & & \\
\hline Less & 22.5 & 2.26 & 1.53 to 3.33 & 0.0001 \\
\hline \multicolumn{5}{|c|}{ Access barriers to condom use } \\
\hline More & 48.1 & & & \\
\hline Less & 26.9 & 1.79 & 1.25 to 2.55 & 0.001 \\
\hline \multicolumn{5}{|l|}{ Impulsivity } \\
\hline High & 38.9 & & & \\
\hline Low & 34.6 & 1.12 & 0.78 to 1.63 & 0.54 \\
\hline \multicolumn{5}{|c|}{$\begin{array}{l}\text { Relational level factors } \\
\text { Partner barriers to condom use }\end{array}$} \\
\hline More & 47.3 & & & \\
\hline Less & 26.5 & 1.78 & 1.24 to 2.56 & 0.001 \\
\hline \multicolumn{5}{|c|}{ Frequency of partner communication about sex } \\
\hline Frequent & 34.0 & & & \\
\hline Infrequent & 39.6 & 1.16 & 0.80 to 1.69 & 0.42 \\
\hline \multirow{2}{*}{\multicolumn{5}{|c|}{ Partner uses hormonal contraceptives }} \\
\hline & & & & \\
\hline No & 36.8 & 0.99 & 0.61 to 1.61 & 0.99 \\
\hline \multicolumn{5}{|c|}{ Peer affiliations } \\
\hline \multicolumn{5}{|c|}{ Ever belonged to a gang } \\
\hline Yes & 43.9 & & & \\
\hline No & 34.7 & 1.27 & 0.90 to 1.79 & 0.18 \\
\hline Most friends r & & & & \\
\hline Agree & 49.2 & & & \\
\hline Disagree & 31.0 & 1.59 & 1.10 to 2.28 & 0.015 \\
\hline Most friends h & & & & \\
\hline Agree & 47.6 & & & \\
\hline Disagree & 31.5 & 1.51 & 1.05 to 2.18 & 0.03 \\
\hline Family level f & & & & \\
\hline Residing with & & & & \\
\hline Yes & 34.2 & & & \\
\hline No & 51.2 & 1.50 & 1.05 to 2.14 & 0.04 \\
\hline Frequency of & parent(s) & & & \\
\hline High & 40.8 & & & \\
\hline Low & 32.7 & 0.80 & 0.55 to 1.60 & 0.24 \\
\hline Perceived leve & & & & \\
\hline High & 38.8 & & & \\
\hline Low & 36.1 & 0.93 & 0.58 to 1.50 & 0.76 \\
\hline Societal level & & & & \\
\hline Condoms are & & & & \\
\hline Yes & 33.6 & & & \\
\hline No & 39.4 & 1.17 & 0.80 to 1.72 & 0.42 \\
\hline Qualify for fre & at schoolf & & & \\
\hline Yes & 42.7 & & & \\
\hline No & 27.3 & 1.57 & 1.05 to 2.33 & 0.02 \\
\hline Witnessed ext & & & & \\
\hline Yes & 38.3 & 0.99 & 0.68 to 1.42 & 0.99 \\
\hline No & 38.5 & & & \\
\hline
\end{tabular}

*Prevalence ratio.

tConfidence interval.

$\ddagger$ This variable served as a proxy measure of income.

$\S$ This variable (exposure to violence and crime) served as a proxy measure of risky social environments. 
not use condoms were about twice as likely to report lack of use $(\mathrm{AOR}=2.05 ; 95 \% \mathrm{CI}=1.01$ to $4.18 ; \mathrm{p}=0.048)$.

\section{DISCUSSION}

Upon investigating multiple levels of potential influence on condom use, our multivariate findings suggest that personal level factors may be an important determinant of non-use among adolescent males in short term detention facilities. Low motivation to use condoms was an especially important correlate. Similarly, a personal propensity towards risk taking may be reflected in adolescents' reports that they had ever caused a pregnancy. This propensity could explain the observed multivariate association between causing a pregnancy and current lack of condom use. Although affiliating with peers who do not use condoms is not a personal level determinant, behavioural intervention aimed at the personal level may, none the less, have an influence of the perception of these norms or may indirectly impact the norms of the peer network.

Although the relational level subscale of the CBS did not retain significance in the multivariate model, the bivariate significance of this correlate is, none the less, intriguing. This finding suggests that adolescent males may base condom use decisions (in part) on the potential reactions of their female sex partners. Thus, even though condom use is a volitional behaviour for males, they may, none the less, engage in some degree of dialogue and negotiation regarding whether a condom will be used. Whether (and to what degree) this dynamic influences the motivation level of adolescent males to use condoms is an important question for future research.

Several of the non-significant findings also deserve comment. For example, adolescents ever having an STI were no less likely to report non-use of condoms. This null finding suggests that the experience of having an STI may not have a subsequent impact on condom use of detained adolescent males. The lack of a relation between impulsivity and condom use was somewhat surprising in light of previous research findings based (in part) on samples of detained adolescent males. ${ }^{16}$

\section{Limitations}

Findings are limited by the validity of the self reported measures and the use of a convenience sample. Further, employing a "last event" recall period for condom use may or may not be fully representative of adolescents' typical frequency of condom use. Indeed, the selection of an "ideal" recall period for condom use behaviours has typically been problematic. 22 The findings are also limited by low statistical power for two correlates that may have achieved significance given a larger sample size. One third of the minority adolescents reported lack of recent condom use compared to $43.5 \%$ of the white, non-Hispanic adolescents. The protective prevalence ratio (that is, 0.76 ) is moderate, but given the sample size this difference did not achieve statistical significance (that is, the obtained $p$ value was $0.11)$. The same phenomenon applies to the non-significant $(p=0.18)$ association between gang membership and lack of condom use. Although the association was in the expected direction and the difference was substantial, the small sample may preclude detecting statistical significance. Finally, it is critically important to note that the findings are very much a product of the measures that were selected. An expanded set of measures for each of the five levels may have yielded substantially different findings.

\section{Implications and conclusions}

Detained adolescent males represent a valuable opportunity (and corresponding challenge) to professionals who serve the goals of public health. ${ }^{74-26}$ Their temporary (court ordered) assignment to a government facility is an opportune time to intervene with respect to their acquisition of safer sex behaviours, including the consistent use of condoms for the prevention of STIs and pregnancy. As opposed to interventions for adolescent females, prevention programmes for males may be quite different because males have direct control over condom use (as opposed to females who must engage in negotiation to achieve condom use). If adolescent males (more so than adolescent females) act as bridges between sexual networks and serve as core transmitters within sexual networks, then promoting condom use among this population may be a practical strategy for also protecting females against STI acquisition.

The findings also relate to questions of whether structural interventions are needed to optimally promote safer sex behaviours. Although structural changes may be needed to influence some forms of safer sex behaviour, findings from this study of detained adolescent males suggest that direct intervention with adolescent males may be justified if the goal is to favourably alter the determinants of condom use. Further research should identify effective intervention programmes that can be used to promote safer sex behaviours among adolescent males during brief periods of court ordered detention.

\section{Authors' affiliations}

R Crosby, College of Public Health, University of Kentucky, KY, USA L F Salazar, R J DiClemente, Rollins School of Public Health, Emory University, GA, USA

R J DiClemente, Emory Center for AIDS Research, Emory University School of Medicine, Department of Pathology and Laboratory Medicine, Emory University School of Medicine, Department of Pediatrics, GA, USA

This research was supported in part by the Emory Center for AIDS Research (NIH/NIAID 2 P30 Al50409-04A1), the Rural Center for AIDS/STD Prevention at Indiana University, and a grant from the University Research Council at Emory University.

\section{REFERENCES}

1 In: Eng TR, Butler WT, eds. The hidden epidemic: confronting sexually transmitted diseases. Washington, DC: National Academy Press, 1997.

2 Centers for Disease Control and Prevention. Sexually transmitted disease surveillance, 2000. Atlanta, GA: Department of Health and Human Services, 2001.

3 Berman SM, Hein K. Adolescents and STDs. In: Holmes KK, Sparling PF, Mardh $\mathrm{P}$, et al, eds. Sexually transmitted diseases. New York: McGraw Hill, 1999:129-42.

4 Centers for Disease Control and Prevention. HIV/AIDS education and prevention programs for adults in prisons and jails and juveniles in confinement facilities - United States, 1994. Morb Mortal Wkly Rep 1996;45:268-71.

5 Oh MK, Cloud GA, Wallace LS, et al. Sexual behavior and sexually transmitted diseases among male adolescents in detention. Sex Transm Dis 1994:21127-32

6 Canterbury RJ, McGarvey EL, Sheldon-Keller AE, et al. Prevalence of HIVrelated risk behaviors and STDs among incarcerated adolescents. J Adolesc Health 1995: 17:173-7.

7 Crosby RA, DiClemente RJ, Staples-Horne M. Health issues of juvenile offenders. In: Moore J, ed. Management and administration of correctional healthcare. Kingston, NJ: Civic Research Institute, 2003:11-1-11-12.

8 DiClemente RJ, Crosby RA. Sexually transmitted diseases among adolescents: Risk factors, antecedents, and prevention strategies. In: Adams GR, Berzonsky M, eds. Blackwell handbook of adolescence. Oxford: Blackwell Publishers, 2003:573-605

9 Crosby RA, Kegler MC, DiClemente RJ. Understanding and applying theory in health promotion practice and research. In: DiClemente RJ, Crosby RA, Kegler M, eds. Emerging theories in health promotion practice and research. New York: Jossey-Bass Wiley, 2002:1-15.

10 Centers for Disease Control and Prevention. Facts about condom and their use in preventing HIV infections and other STDs. Atlanta, GA: United States Department of Health and Human Services, 1996.

11 Turner CF, Ku L, Rogers SM, et al. Adolescent sexual behavior, drug use, and violence: increased reporting with computer survey technology. Science 1998;280:867-71

12 Kissinger P, Rice J, Farley T, et al. Application of computer-assisted interviews to sexual behavior research. Am J Epidemiol 1999;149:950-4.

13 Michaud P, Narring F, Ferron C. Alternative methods in the investigation of adolescents' sexual life. J Adolesc Health 1999;25:84-90. 
14 St Lawrence JS, Chapdelanie AP, Devieux JG. Measuring perceived barriers to condom use: psychometric evaluation of the Condom Barriers Scale. Assessment 1999;6:391-404.

15 Crosby RA, DiClemente RJ, Wingood GM, et al. Identification of strategies for promoting condom use: a prospective analysis of high-risk African American female teens. Prev Science 2003;4:263-70.

16 Pack R, Crosby RA, St Lawrence JS. Association between adolescents' sexual risk behavior and scores on six psychometric scales: Impulsivity predicts risk. J HIV/AIDS Prev Edu Adolesc Child 2001;4:33-47.

17 Crosby RA, DiClemente RJ, Wingood GM, et al. Condom use and correlates of African American adolescent females' infrequent communication with sex partners about preventing sexually transmitted diseases and pregnancy. Health Educ Behav 2002;29:219-31.

18 Cooper ML, Agocha VB, Powers AM. Motivations for condom use: do pregnancy prevention goals undermine diseases prevention among heterosexual young adults? Health Psych 1999;18:464-74.

19 Wingood GM, DiClemente RJ, Crosby RA, et al. Gang involvement and the health of African-American female adolescents. Pediatrics 2002;110:e57-e61.
20 Crosby RA. Miller KS. The pivotal role of the family on adolescent females' sexual health. In: Wingood GM, DiClemente RJ, eds. Handbook of women's sexual and reproductive health. New York, Kluwer Academic/Plenum Publishers, 2002:113-28.

21 Zimet GD, Dahlem NW, Zimet SG, et al. The multidimensional scale of perceived social support. J Personality Assessment 1988;52:30-41.

22 Crosby RA, DiClemente RJ, Holtgrave DR, et al. Design, measurement, and analytic considerations for testing hypotheses relative to condom effectiveness against non-viral STls. Sex Transm Infect 2002;78:228-31.

23 Crosby RA. Condom use as a dependent variable: measurement issues relevant to HIV prevention programs. AIDS Educ Prev $1998 ; 10: 448-457$

24 Anderson B, Farrow JA. Incarcerated adolescents in Washington State, health services and utilization. J Adolesc Health 1998;22:363-7.

25 Feinstein RA, Lampkin A, Lorish CD, et al. Medical status of adolescents at time of admission to a juvenile detention center. J Adolesc Health 1998;22:190-6.

26 Hein K, Cohen MI, Litt IF, et al. Juvenile detention: another boundary issue for physicians. Pediatrics 1980;66:239-45. 